\title{
Representación del indígena en Twitter. Caso: Mushuc Runa Sporting Club
}

\author{
Indigenous representation on Twitter. \\ Case: Mushuc Runa Sporting Club \\ Representação indígena no Twitter. \\ Caso: Mushuc Runa Sporting Club
}

\author{
Alfredo Bagua \\ FLACSO (Quito, Ecuador) \\ alfredbagua@gmail.com \\ https://orcid.org/0000-0001-5885-8200
}

DOI: https://doi.org/10.32719/25506641.2020.7.8

Presentado: 30 de septiembre de 2019 - Revisado: 20 y 21 de octubre de 2019 Aceptado: 9 de noviembre de 2019

Artículo de investigación

Licencia Creative Commons

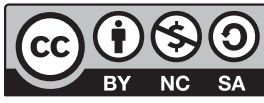




\section{Resumen}

Representar es hablar acerca de, es capturar, enmarcar y construir un archivo cultural para construir un régimen de la verdad que sitúa al indígena como inmóvil, ahistórico y abyecto. En este artículo se busca conocer qué representación aparece en el tuit-texto-discurso del usuario de Twitter en su interacción con Juan Pablo Sorín, bimundialista con la selección de Argentina, quien preguntó por la historia de Mushuc Runa y visitó Ecuador para conocerla. El fútbol representa en este estudio un campo de disputa simbólica y construcción de sentidos, devela racismo, identidades y afectos temporales. Mientras, el indígena del equipo Mushuc Runa circula sus símbolos y matrices culturales para permear al campo de fútbol con la dimensión de la cultura, no solo su aspecto identitario sino también político y económico; su forma de autonomía y emancipación en y con el mundo simbólico logra cuestionar las imágenes y los discursos hegemónicos. El análisis de discurso es usado para evidenciar estos elementos y se requirió un corpus teórico (lenguaje-dispositivo, campo, fútbol, campo y archivo cultural) para alcanzar los objetivos planteados. El archivo cultural no logra indicar un nombre nuevo para este nuevo indígena que dinamiza el fútbol con su matriz cultural, porque los tropos viejos quedan sin poder ante él.

Palabras clave: Representación, indígena, Mushuc Runa, Twitter, cultura, poder, fútbol. JEL: Z: Otros temas especiales; Z13 normas sociales y capital social; redes sociales.

\section{Abstract}

To represent is to "talk about", it is to capture, frame and build a cultural archive to build a "regime of truth" that places the indigenous as immobile, a-historical and abject. This article seeks to know what representation appears in the tweet-text-speech of the Twitter user in his interaction with Juan Sorín, two-time World Cup participant with the National football team of Argentina, who asked and visited Ecuador in order to know the history of Mushuc Runa. Football represents in this study a "field" of symbolic dispute, construction of senses, reveals racism, identity and temporary affections. Meanwhile, the indigenous of Mushuc Runa team circulates their symbols and cultural matrices to permeate the football "field" with the dimension of culture, not only the identity but also political-economic aspect, being their form of autonomy and emancipation with the symbolic world, they achieve to question hegemonic images and speeches. The discourse analysis is used to demonstrate these elements and a theoretical corpus (device-language, field, football, field and cultural archive) was required to achieve the stated objectives. The "cultural archive" fails to indicate a new name for this new indigenous who energizes football with its cultural matrix because the old troops are left without power before him.

Keywords: Representation, indigenous, Mushuc Runa, Twitter, culture, power, football. JEL: Z: Other special topics; Z13 social norms and social capital; social networks. 


\section{Resumo}

Representar é "falar acerca de", é capturar, enquadrar e fazer um arquivo cultural para construir um "regime da verdade" que situa o indígena como imóvel, a-histórico e abjeto. Neste artigo se procura conhecer qual representação aparece no tuíte-texto-discurso do usuário de Twitter em sua interação com Juan Sorín, bicampeão do mundo com a seleção da Argentina, que visitou o Equador para conhecer a história do Mushuc Runa. O futebol representa neste estudo um "campo" de disputa simbólica, construção de sentidos, desvela racismo, identidade(s) e afeto(s) temporais. Enquanto isso, o índio do time Mushuc Runa circula seus símbolos e matrizes culturais para permear o "campo" de futebol com a dimensão da cultura, não somente o aspecto identitário, mas político e econômico, sendo sua forma de autonomia e emancipação em e com mundo simbólico, conseguindo questionar imagens e discursos hegemônicos. A análise de discurso é usada para evidenciar estes elementos e precisou-se de um corpo teórico (linguagem-dispositivo, campo, futebol, campo e arquivo cultural) para alcançar os objetivos propostos. $\mathrm{O}$ "arquivo cultural" não consegue indicar um nome novo para este novo índio que dinamiza o futebol com sua matriz cultural porque as figuras de linguagem velhas ficam sem poder perante ele.

Palavras-chave: Representação, indígena, Mushuc Runa, Twitter, cultura, poder, futebol. JEL: Z: Outros tópicos especiais; Z13 normas sociais e capital social; redes sociais.

\section{Introducción}

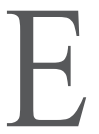

n Ecuador, fútbol e indígena son temas que han sido escasamente estudiados, porque la visión del poder hacia el otro está en el espacio de lo inmóvil, lo arcaico y lo primitivo. Es en este contexto que surge la presencia del equipo Mushuc Runa Sporting Club, liderado por un indígena y desde el año 2003 financiado por una cooperativa del mismo nombre, con capital humano del pueblo Pilahuín. Su participación en la Copa Sudamericana de 2019 tuvo el tinte de histórico.

La escasez de estudios y este hecho tejieron las inquietudes del presente texto, en especial para indagar en qué medida el archivo cultural sobre el indígena es reproducido por el fútbol y sus actores. Se utilizó como recolección de datos la percepción de cómo los usuarios de Twitter se refieren al indígena y al equipo Mushuc Runa Sporting Club, cuánto cambió el archivo cultural con la presencia del Mushuc Runa y Juan Pablo Sorín en Ecuador, y la disputa de poder con el uso de los símbolos culturales en el campo del fútbol, con la pregunta de si es parte del folclor que dinamiza a esta industria cultural. 


\section{Revisión de la literatura}

Desde la perspectiva personal se observa que el fútbol implica afectos, identidades, pasiones, valores y cohesión social temporal; anula las diferencias sociales en países marcados por la pobreza, la desigualdad y la exclusión. El fútbol moviliza cuerpos, marcas, afectos y pasiones de grupos sociales a través de medios locales, regionales y globales que lo convierten en la nueva religión del ser: es practicada en todo el mundo por jugadores de toda clase social, con camisetas diversas -atuendo sagrado- en una cancha de césped, cemento o tierra, que al mismo tiempo se transforma en el templo donde se deleita al hincha-feligrés con una pelota. ${ }^{1}$ La religión tiene al sacerdote-pastor como dueño del saber, poder y control de bienes simbólicos y religiosos: en el fútbol es el técnico el amo de ese saber -táctica, estrategia, disciplina y discurso-, mientras que periodistas, exjugadores y medios son otros expertos, en conjunto con el hincha. ${ }^{2}$

Estas particularidades no fijan al fútbol en un campo aislado de interacción social, sino que lo insertan "en la esfera más amplia de la sociedad y, por lo tanto, establecen relaciones con el campo de la política, de la economía, etc." (Oliven y Arlei 2001, 26). También está atravesado por la cultura que circula en su discurso: este deporte masivo reproduce discursos y prácticas ancladas en un "archivo cultural de historias, artefactos, ideas, textos y/o imágenes que son clasificados, preservados, organizados y presentados de nuevo a Occidente" (Tuhiwai 2016, 25).

En el archivo cultural circula un sistema simbólico de clasificación y representación basado en concepciones de raza, género, espacio y tiempo que evidencian la naturaleza, la moralidad y la virtud humana -sean reales o no- en diversos contextos y discursos, y devienen en sistemas de poder y dominación sobre poblaciones indígenas salvajes, oprimidas, que deben ser disciplinadas, educadas e insertadas en la sociedad mediante la espada, el

1. El texto de Zarza (2017) resitúa la expresión latina "pan y circo", siendo el fútbol entendido como instrumento de distracción a partir de un tipo de dominio del poder, porque este deporte combina lo festivo y el sentimiento de unidad, características necesarias para construir identidades alrededor del fútbol en el mundo contemporáneo.

2. Sergio Villena (2009) explora acerca del discurso de los jugadores, del cuerpo técnico y de los aficionados entorno a la selección y cómo en ella aparece la dimensión religiosa. 
látigo, la Biblia y la educación, entre otros instrumentos del discurso racista y colonial circulados, fijados y legitimados por la modernidad, según señala Tuhiwai (2016).

Pues bien, el lenguaje es un instrumento eficaz para hablar de, disciplinar, civilizar al otro: reactualiza imágenes y textos históricos del ser, es un dispositivo que enmarca, describe, altera y fija realidades a través de signos, imágenes, símbolos y significados que diseñan, estructuran y construyen relatos, discursos e imaginarios sociales. Con este acervo simbólico ocurre la interacción del ser humano en el mundo social.

Los hinchas, el poder y los medios de comunicación construyen discursos y prácticas de representación para crear imágenes y conocimiento que devienen en verdad acerca del originario, pero es una verdad atravesada por el racismo, la xenofobia y el miedo al indígena de rostro cobrizo que vive en la pobreza.

La verdad del hincha es producto del archivo colonial de imágenes de representación del otro circulados por el poder, los medios, la política, la religión y la educación, instituciones que legitiman y transforman el discurso en régimen de verdad en torno al indígena, lo que incide en prácticas e imaginarios sociales y logra establecer las relaciones de poder. Este discurso, este conocimiento y esta verdad forman un tejido simbólico poderoso deconstruido por las prácticas y políticas de resistencia encarnadas en las acciones y los discursos del equipo de fútbol Mushuc Runa Sporting Club.

La representación del indígena ocurre en el lenguaje, entendido por Agamben como el dispositivo - un "conjunto heterogéneo, que incluye virtualmente cualquier cosa, lo lingüístico y lo no lingüístico, al mismo título: discursos, instituciones, edificios, leyes, medidas de policía, proposiciones filosóficas, etcétera" $(2014,1)$ - que controla, modela y contamina la vida del individuo. Este dispositivo se da en las relaciones de poder y en espacios concretos; para nuestro estudio, inferimos que son hinchas, periodistas, exjugadores de fútbol, directivos y técnicos que se disputan espacios de poder en el campo del fútbol dominado por el blanco-mestizo. Es una red que logra la producción de sentido ligado a conceptos fijados en la mente del hincha mediante el lenguaje. Este permite la interacción del indígena con los actores del fútbol desde 2013 hasta el desarrollo de esta investigación.

Por tanto, ¿qué tipo de representación del otro apareció en las redes sociales y los medios de comunicación que se logró fijar como verdad? ¿Cuál 
fue el discurso de respuesta del indígena? Hay que tomar en cuenta que "representación es producción de sentido, es el vínculo entre los conceptos y el lenguaje, es el que nos capacita para referirnos al mundo real de los objetos, de la gente o de los eventos, o para referirnos a los mundos imaginarios de los objetos, de la gente y de los eventos ficticios" (Hall 1997, 4). La producción de sentido está ligada al archivo cultural que circula y sitúa imágenes del indígena en el lenguaje, es la cara opuesta de Occidente y del poder blanco-mestizo, binario opuesto y complementario hasta estigmatizar al originario.

Ahora bien, hablar de, representar, se entiende como un proceso comunicativo desde la cultura

que nos permita pensar los nuevos procesos de socialización [...] a través de los cuales una sociedad se reproduce, esto es, sus sistemas de conocimiento, sus códigos de percepción, valoración y de producción simbólica de la realidad. Lo cual implica -y esto es fundamental- empezar a pensar los procesos de comunicación no desde las disciplinas, sino desde los problemas y las operaciones del intercambio social, esto es, desde las matrices culturales de identidad y los conflictos que articula la cultura. (Martín-Barbero 2012, 80)

Poncho, lengua kichwa, cuy y minga son elementos de identidad y discursivos circulados por Mushuc Runa Sporting Club en el campo del fútbol para disputar significados y sentidos con el archivo cultural dominante desde 1899, año en que llegó la primera pelota a Ecuador (StudioFútbol 2013). La disputa es simbólica, discursiva, económica y política, e insta a ver al fútbol desde la cultura y ya no solo desde lo lúdico, el ocio o el negocio.

El discurso es un instrumento que devela los usos que el poder hace de los medios de comunicación, la palabra y la imagen y que impactan sobre los miembros de una sociedad. También implica los mecanismos de resistencia circulados por los dominados en la interacción comunicativa, porque la palabra-lenguaje posee la capacidad de crear espacios, medios y formas de dominación y resistencia.

Por lo tanto, el análisis del discurso es un instrumento que permite entender las prácticas discursivas que se producen en todas las esferas de la vida social de las que el uso de la palabra -oral y escrita- forma parte (Calsamiglia y Tusón 2002). Además, con el análisis crítico de discurso (ACD) se estudia "el modo en que el abuso del poder social, el dominio y la desigualdad 
son practicados, reproducidos, por los textos y el habla en el contexto social y político" (Van Dijk 1999, 24).

El discurso es parte de la vida social, es un instrumento que crea la vida en la dimensión social y cultural del ser en el mundo de la vida, es el lenguaje que conecta la cultura y la sociedad, el instrumento y el medio para la interacción social en tiempos y espacios cotidianos. Por ende, es crucial conocer al lenguaje, que forma una ligazón entre la cultura y las prácticas de representación. El lenguaje circula cultura, miedos y apreciaciones del otro; esta circulación se da en texto-palabra, imagen y voz, mediada por internet, el nuevo medio de comunicación en que convergen los mass media: "La red de redes funciona como un medio masivo, continuo e interactivo al que pueden acceder distintos usuarios de modo sincrónico y asincrónico, por lo que representa un sistema conector del sistema multimedia, que permite una comunicación horizontal de ciudadano a ciudadano" (Alcalá 2017, 409).

La red es un elemento central en la comunicación humana. No puede estar focalizada en pocos espacios o lugares sociales, porque fue creada como instrumento de comunicación de libre acceso; sin embargo, aparece la divisoria digital cuando, al encontrarse con información y comunicación en la red, uno no cuenta con las habilidades para buscarlas y transformarlas en conocimiento (Castells 2001).

Pues bien, nuestro objeto de estudio será la red social, entendida como "un conjunto bien definido de actores, individuos, grupos, organizaciones, sociedades globales, etc., que están vinculados unos a otros, a través de un conjunto de relaciones sociales, simplificadas, en el caso informático, por el uso de las nuevas tecnologías" (Muñoz y Argüelles 2010, 711). Comunicación, comunidad y cooperación son aspectos positivos ponderados desde diversas disciplinas por los estudios sobre las redes sociales, que subrayan su relación con el usuario, quien ha aprendido e incorporado ciertas habilidades para ser parte de una práctica social. No obstante, es necesario señalar la ambivalencia, las tensiones que provoca el acto de poner en común dos universos simbólicos opuestos, encontrar e integrar una comunidad por identidad y hacer, de manera conjunta, actividades en la red en tiempos y espacios temporales y ubicuos.

Por tanto, los conceptos de cultura, comunicación, representación, discurso, poder y dispositivo permiten conocer la representación del indígena en la red social Twitter. 


\section{Materiales y métodos}

En este trabajo se utilizó la metodología cualitativa del análisis de discurso. El universo de estudio son los tuits publicados por Juan Pablo Sorín previo y durante el debut de Mushuc Runa en la Copa Sudamericana, así como los tuits de respuesta de los aficionados. El objetivo es conocer la representación del indígena en las redes sociales a través del uso de la imagen, el video o la palabra.

Diálogo, texto, contexto, poder social y otros elementos discursivos de los tuits se analizaron para determinar la representación del indígena en el fútbol ecuatoriano a partir del uso del archivo colonial circulado, apropiado y reproducido por los usuarios de la red. También se buscó conocer cómo, en la relación entre poder y discurso, el indígena circula su cosmovisión, sus matrices culturales y símbolos como disputa simbólica y construcción de sentidos en el campo del fútbol.

\section{Análisis y resultados}

\section{De la imagen grabada a la imagen virtual}

La producción de imágenes sintetiza y comunica cultura y prácticas de la época. La pintura rupestre es el primer registro de comunicación de la humanidad. Se plasmó alrededor del 30.000 a. C., y constituye "un medio de comunicación a dos niveles: con otros seres humanos y con la divinidad" (Gil 2009, párr. 1) y "su producción consiste en una acción consciente para modificar simbólicamente el paisaje, y eran portales de entrada al mundo sobrenatural" (Amador 2018, 2). Después, la comunicación estaría mediada por el pictograma (5000 a. C.) y, más tarde, la acuñación sería un elemento de comunicación y propaganda: "Si la autoridad es monárquica, la moneda es un instrumento de prestigio personal, y el monarca mandará a poner su efigie en ella; así lo hicieron los reyes helenísticos y César" (Manzanero 2000, párr. 4 del ítem 14).

Los líderes religiosos fariseos, ligados al poder político, preguntaron a Jesús si era lícito o no pagar impuestos al César. En Marcos 12:16, Jesús pide 
una moneda y pregunta “¿De quién son esta imagen y esta inscripción?” "Del César", le contestan. ${ }^{3}$ La imagen y la inscripción hacen circular un discurso de poder, cultura y lenguaje simbólico en comunidades y culturas dominadas por el Imperio romano; es una representación que construye sentidos y logra diseñar la geografía e historia visual del ser.

La imagen del César grabada es poder, es una parte de la totalidad; la circulación de la moneda es el poder diseminado en todas las capas sociales. Él no está en Jerusalén, Cafarnaúm, Galilea..., pero está en la imagen y la palabra, dos dispositivos de representación, dominación y diferenciación sociocultural que sujetan voluntades y subjetividades obedientes, moldeadas y sumisas al poder.

En la Edad Media, "el ícono, información sacra, se inscribe en un orden inteligible entre lo representado y el espectador” (Velásquez 2006, 17): la imagen instaura orden, jerarquía y obediencia. Con la aparición de la imprenta de Gutenberg, la imagen pasa al libro acompañada de la escritura, que divide a la sociedad en alfabetos y analfabetos. Platón considera a "la escritura como una tecnología externa y ajena. La escritura inició lo que la imprenta y la computadora continúan: la reducción del sonido dinámico al espacio inmóvil y la separación de la palabra del presente vivo" (Ong 1987, 84). La tecnología de la escritura genera una transformación interna de la conciencia.

Volviendo a la imagen, ella es el centro en el cine, la televisión e internet; imagen, palabra y sonido son la tríada constructora de imaginarios y discursos del otro basados en el archivo cultural de la dialéctica: identidad/alteridad, yo/civilizado versus otros/salvajes. El poder circula la representación del otro, es objeto de opresión y dominio, es una posición social determinada, arbitraria y vertical, que justifica las políticas y acciones civilizatorias ocurridas en la historia desde 1492.

Las acciones, prácticas y formas de poder están conectadas a las representaciones para construir identidad, establecer fronteras simbólicas, sociales y culturales entre el poder y los originarios. La diferencia es central en la identidad; sin embargo, no es fija, sino que se mueve acorde al contexto social dominante y tiene aspectos positivos y negativos (Hall 2010, 243).

3. Este relato también aparece en el Evangelio de Lucas (20:20-26). 
La representación identitaria del originario en la Conquista lo pinta como manso, bondadoso, y más tarde esas virtudes son vicios: la mansedumbre es cobardía, la desnudez es natural. En la Colonia, el indio cambia de significado porque es el enemigo, necesita ser civilizado; da así origen al indio salvaje y caníbal. Ya en la República, los naturales son sumisos, bárbaros, abyectos y miserables (EC 1830); en el siglo XIX, el indio es bestia de carga, pagano exótico y subversivo (Muratorio 1994), "es analfabeto y borracho, necesita ayuda del poder político y religioso, es una raza redimible e infeliz, pero cuando lucha por la tierra el indígena es peligro, amenaza" (Endara 1998, 29).

Este archivo cultural de imágenes e imaginarios del poder hacia el indígena no sufrió ningún cambio en la época de la Revolución Ciudadana, cuando fue representado y estigmatizado como infantil en un Estado que reconoce la interculturalidad y la plurinacionalidad (EC 2008, art. 1).

¿En qué medida los usuarios de las redes sociales reproducen el archivo cultural en su representación del indígena? El indio insertado en el sistema del blanco, ¿no genera un aindiamiento del blanco sino su propio blanqueamiento? ¿En qué medida las redes sociales permiten rupturas o continuidades de la representación del indígena en el fútbol ecuatoriano? ¿Cuánto incide la percepción del extranjero -Juan Pablo Sorín- en la mirada del ecuatoriano -hincha, periodista- hacia los logros y símbolos culturales del equipo Mushuc Runa?

Estas preguntas guían el estudio de caso de los tuits del exjugador profesional y hoy comentarista deportivo Juan Pablo Sorín, quien ponderó y siguió la participación del equipo indígena Mushuc Runa en la Copa Sudamericana, torneo de clubes organizado por la Confederación Sudamericana de Fútbol (Conmebol). Sorín, tuitero, se declaró fan de Mushuc Runa entre diciembre de 2018 y febrero de 2019.

Ahora bien, desde su aparición en 1994, internet, más que una tecnología de comunicación, se ha convertido en una tecnología de representación del nuevo siglo. La construcción ficcional del yo está siendo sustituida allí por la reconstrucción y el reconocimiento del sujeto en sus prácticas virtuales, porque es creador de contenidos. 
Las nuevas formas de representación simbólica que están surgiendo en el espacio virtual de Internet están dando lugar a nuevas formas de privacidad, de identidad personal y colectiva y, en suma, a nuevas relaciones sociales, como pone de manifiesto la utilización de espacios o comunidades virtuales tales como YouTube, MySpace, Hi5 o Facebook. Por ello lo virtual y lo real no deben ser entendidos como dos categorías opuestas, ya que la cultura digital es en gran medida una extensión del concepto de cultura, donde lo virtual efectivamente propone "otra" experiencia y otro análisis de lo real que nos obliga a una mejor comprensión de los lazos y nudos que enlazan las realidades y las apariencias, las ilusiones y los síntomas, las imágenes y los modelos. Lo virtual no sustituye a lo real sino que lo representa, es un laboratorio de experimentación ontológica que nos obliga a renunciar al apoyo de las apariencias y nos vuelve cazadores de lo real en bosques de símbolos. (Moreno y Suárez 2010, 6)

En ese bosque de símbolos de representación está el equipo de fútbol Mushuc Runa, que significa 'hombre nuevo'. ${ }^{4}$ Con siete años de vida institucional en el fútbol profesional ecuatoriano, tiene un estadio con cancha reglamentaria y capacidad para 21.000 aficionados (El Comercio 2018b), cuya construcción se llevó a cabo a través de la minga. Este término representa el trabajo colectivo de una comunidad sin remuneración económica, porque minga, en el mundo andino, es solicitar ayuda prometiendo algo, "es una alternativa de subsistencia colectiva fundada en el principio de la reciprocidad que coexiste con las consecuencias del capitalismo" (López 2018, 9).

La reciprocidad teje y da vida a la minga de construcción del estadio, que sirve "para elevar la autoestima del indígena", expresa Chango (2019, 06:38; 17:21). Es materializar el para sí y para otros del pensamiento andino en el fútbol, es palabra creadora de compromisos en el capitalismo excluyente. Con esto, la minga de Mushuc Runa no es antítesis del sistema individualista ni está al margen del capitalismo, sino que interactúa en el sistema hegemó-

4. El club Mushuc Runa es auspiciado por la Cooperativa de Ahorro y Crédito Mushuc Runa. Su presidente vitalicio es Luis Alfonso Chango, abogado, que inició su andar en el fútbol a los 8 años y formó el equipo Técnico San Luis a los 13. Con los empleados de la cooperativa, decidió participar en torneos parroquiales de Tungurahua en 2003; dos años más tarde se afilió a la Asociación de Fútbol de Tungurahua para jugar con equipos de la serie A del fútbol ecuatoriano, idea que se cristalizó en 2013. Descendió a la serie B en 2016 y volvió a ascender en 2018. Durante la elaboración de la indagación participa en la serie A de la LigaPro, ente del fútbol profesional del Ecuador, y es miembro de la Federación Ecuatoriana de Fútbol afiliada a Conmebol (regional) y FIFA (mundial). 
nico, pero con sus símbolos y matrices culturales disputa y construye sentidos de comunidad, tejido social e identidad en el campo del fútbol.

Nosotros hacemos todo lo contrario de lo que dice que debemos hacer estadios en las grandes ciudades, sino [que] estamos construyendo un estadio en la comunidad Echa Leche, sector de Pilahuín, Tungurahua. Tenemos un proyecto social de incluir al indígena en el fútbol para sacar jugadores, narradores, comentaristas kichwas, canal de televisión, fábrica de camisetas, hoteles, restaurantes, para reactivar la economía de nuestras comunidades rurales. (Chango 2019, 13:30; 17:25-32)

El proyecto social del equipo tungurahuense tiene diferentes fases: fútbol gratuito, hábitos de fútbol, vicio del fútbol y fútbol profesional en la comunidad. Esta planificación sistemática crea un habitus de consumo del fútbol en el mundo rural. Es la coexistencia de dos mundos que dan origen a otra comunidad indígena ligada al fútbol.

Mushuc Runa es un activo intangible, ${ }^{5}$ es una marca ligada a un proyecto social, característica que no tienen otros equipos profesionales del fútbol ecuatoriano, que apuntan a la compraventa de jugadores, a la fidelización de hinchas, es decir, al fútbol como negocio. En cambio, Mushuc Runa busca cambiar la vida del indígena y su comunidad, desde su autoestima hasta su vida cotidiana, creando un habitus y una cultura del fútbol (Chango 2019); es una propuesta que "rompe el esquema tanto en lo futbolístico y cultural" (Tixi 2018, 82).

En el año 2019, Mushuc Runa ganó el derecho a participar en la Copa Sudamericana tras ganar, en la fase previa del torneo, a Sociedad Deportiva Aucas. Los directivos Karina Chango y Segundo Pilamunga, directivos del Mushuc Runa, paridad andina, ${ }^{6}$ participaron en el sorteo del torneo en

5. El 40\% de los auspicios de Mushuc Runa proceden, como se dijo, de la Cooperativa Mushuc Runa; además, tiene seis auspicios de otras cooperativas (San Francisco, Chibuleo, Ambato, Daquilema y Kullki Wasi). Mushuc Car y Mushuc Wasi, entre otras empresas, financiaron su participación en el fútbol profesional en 2019. La Cooperativa Mushuc Runa auspicia asimismo otras disciplinas deportivas del Ecuador - para lo cual destina dos millones de dólares anuales-, tiene ganancias que superan los seis millones y paga un millón en impuestos al Estado.

6. Paridad andina es la relación y coexistencia entre hombre y mujer. Está regido "en principio hay dos elementos diferentes, dos esencias que entre otras características tienen la de ser complementarias y proporcionales, componen dos cosmos paralelos pero combinados; en donde la unidad no existe sino en tanto que tiene un correlato o contraparte que la equipara o des-equi- 
Luque, Paraguay, el 18 de diciembre de 2018, vestidos con su ropa tradicional. Además, entregaron un poncho, indumentaria del pueblo Chibuleo, de la provincia de Tungurahua, a Alejandro Domínguez, presidente de la Conmebol. "Fue algo emotivo para nosotros como dirigentes del Mushuc Runa. La entrega de la indumentaria mostró la cultura y diversidad de los pueblos que están presentes en el fútbol internacional indicó la vicepresidenta del club Karina Chango" (Bendito Fútbol 2018).

\section{Imagen 1 \\ Alejandro Domínguez, presidente de la Conmebol (centro), vistiendo el poncho de Mushuc Runa}

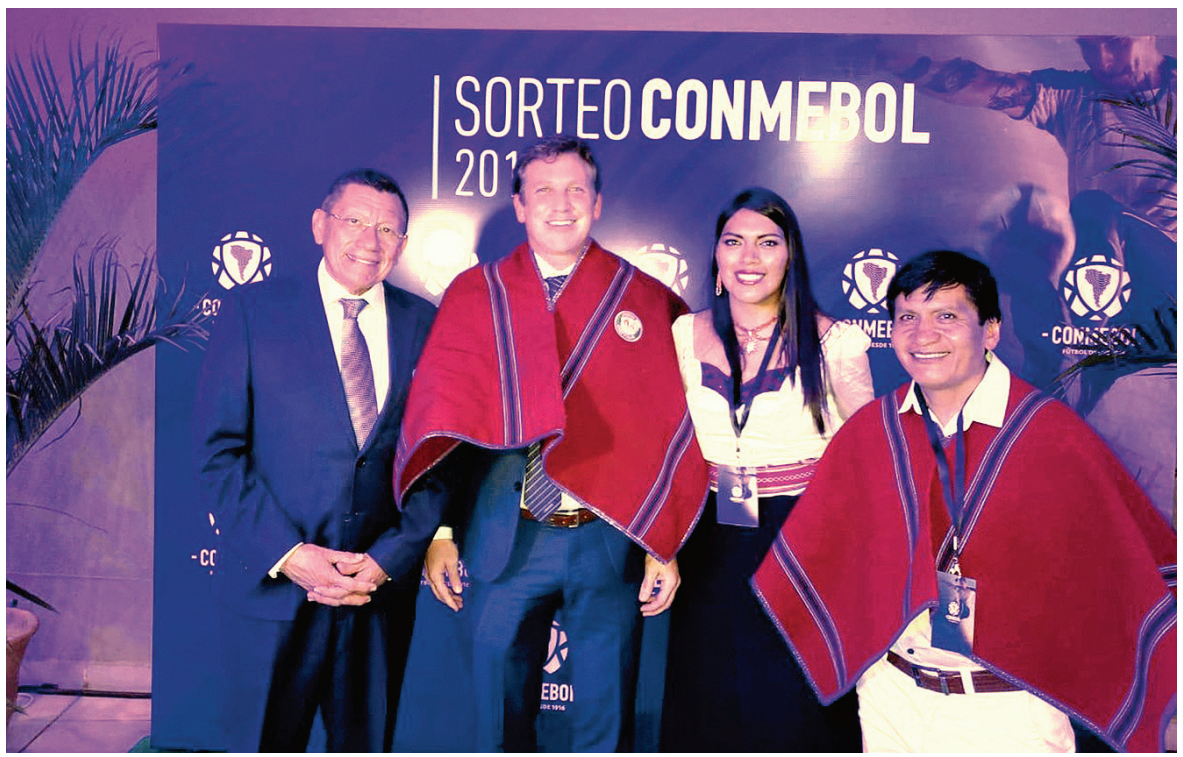

Fuente: cuenta de Twitter del club Mushuc Runa, 17 de diciembre de 2018 (https://bit.ly/2ED9qMD).

para [...] en el mundo indígena todo es par, lo que se presenta como impar (chu'ulla en idioma puquina) existe sólo aparente o transitoriamente, son estados de transición momentánea" (Lajo, 2006, 145). En las comunidades indígenas del Ecuador aparece lo par (hombre-mujer) e impar (soltero/a) que tejen la vida social de las comunidades. 
La entrega de un poncho, símbolo impuesto a los pueblos andinos, es una práctica sociocultural del indígena hacia personas -indígenas, mestizas o afrodescendientes- por su lugar, posición social y nivel de afectividad o gratitud en y para la comunidad. Es la reciprocidad comunitaria materializada, porque el poncho es una parte que contiene, representa y significa el todo (aprecio, respeto, honra, gratitud, admiración, comunidad, saber y memoria). Es un todo ligado a la palabra, ya que todo está conectado en el mundo andino nada está suelto. Por ende, es su discurso simbólico y político que tensiona y cuestiona las miradas acerca del otro alimentadas por archivos culturales hegemónicos en campo del fútbol.

Pilamunga y Chango, paridad andina, están inmersos en el fútbol individual y machista representado por Domínguez, presidente de la Confederación Sudamericana de Fútbol (Conmebol), y Villacís, presidente de la Federación Ecuatoriana de Fútbol (FEF), (imagen 1). El poncho y la paridad andina resignifican el campo del fútbol; es una resignificación de pervivencia cotidiana, un cuerpo a cuerpo entre símbolos de la modernidad y del mundo andino, para dar origen a otro indígena distante del ser "abyecto y miserable" de la primera Constitución de la República del Ecuador.

En el imaginario social cotidiano, desde el poder, el poncho es símbolo de representación del indígena, pero en el fútbol toma otro significado al ser usado en la firma y presentación de jugadores y técnicos, a través de los medios. Mientras, Barcelona, Liga de Quito, Emelec, El Nacional y Macará, entre otros, realizan la presentación de sus fichajes con indumentaria oficial, ritual del fútbol contemporáneo, en rueda de prensa, con cobertura de medios locales y oficiales de los equipos de fútbol (redes sociales y televisión).

Además, Mushuc Runa despierta la mirada del poder porque el indígena, sea directivo, hincha y/o jugador, está en el fútbol auspiciado por un ente financiero propio, la Cooperativa Mushuc Runa. No tiene apoyo de ninguna entidad pública, privada o deportiva -Ministerio del Deporte, Federación Ecuatoriana de Fútbol (FEF) o alguna asociación de fútbol provincial-de las que dicen velar por masificar el fútbol en el país.

Durante esta investigación, el Estado socializó el programa Juego Limpio 2030, que entregará 1.000 canchas, y busca ser sede de la Copa del Mundo 2030 junto con Colombia y Perú. Esta propuesta de masificación del fútbol apunta al uso adecuado del tiempo libre para prevenir el uso y consumo 
de drogas, y erradicar la violencia. El fútbol es deporte, juego, espectáculo y propaganda para el poder, pero para Mushuc Runa es presencia estratégica y posicionamiento de una marca con un proyecto social. Fútbol e identidad forman su discurso; el fútbol-modernidad es apropiado, jugado y resignificado por el andino desde sus matrices culturales.

Ahora bien, la entrega y puesta del poncho es un proceso comunicativo que, en el poder económico, deportivo y cultural representado por Domínguez, es hibridación temporal, porque después volverá a su habitus y matrices dominantes. Imagen escasa en el fútbol, el poncho es identidad, pero identidad refinada, que está y juega en la dinámica de la matriz colonial capitalista de consumo de bienes simbólicos sin dejar de ser indígena, aunque él está ligado a lo salvaje desde la visión hegemónica. Es así que él llega a existir para el poder "en virtud de esta dependencia fundamental de la llamada del otro [...] Los términos que facilitan el reconocimiento son ellos mismos convencionales, son los efectos y los instrumentos de un ritual social que decide, a menudo a través de la violencia y la exclusión, las condiciones lingüísticas de los sujetos aptos para la supervivencia" (Butler 2004, 22).

Violencia y exclusión son lugares cotidianos para el indígena, tanto en el lenguaje como en la realidad, porque el archivo cultural de su representación está atravesado por estos efectos. Sin embargo, Mushuc Runa logra volver porosos los espacios de exclusión y racismo reproducidos por el fútbol y el lenguaje. En ese lugar, Chango apunta a materializar su proyecto deportivo: "Ser campeones de la Serie A, jugar la Copa Libertadores y promover a jugadores de las comunidades indígenas. Nosotros trabajamos técnicamente y nos basamos en los ingresos económicos del equipo" (El Comercio 2018a).

Su participación en el fútbol profesional articula una forma de resistencia política y reinvierte los efectos de su representación por el poder. Resistir reinvirtiendo es un proceso de apropiación del fútbol y su lógica, evidencia su conciencia de sujeto social, histórico y político que elabora un discurso con símbolos impuestos y propios en el campo del fútbol. Resiste a perder quién es y su autonomía en el campo del fútbol; reinventa el poncho, impuesto en la Colonia como signo de clasificación social, pero símbolo cultural de un pueblo originario, ancestral, heterogéneo y vigoroso en el mundo globalizado. Es un giro al significado del poncho, del fútbol y del ser indígena en el fútbol, pero en la dimensión del tiempo andino, que se basa en el "pachakuti, la vuelta 
del tiempo, pero esta vuelta del tiempo es un cambio total, no volver a repetir lo que ya pasó" (Spedding 2008, 35). El indígena busca su devenir en el tiempo circular porque es otro indígena con pasado rural y presente urbano; ambos coexisten en él para resignificar el uso social del poncho, del fútbol y de las matrices culturales, en una práctica para "abrir zonas de autonomía y emancipación en/con nuestras prácticas personales y colectivas" (Rivera 2015).

Mushuc Runa es autonomía y emancipación de imagen, discurso personal y colectivo del pueblo Pilahuín, porque su equipo de fútbol conecta a la comunidad, crea afectos y simpatías de propios y extraños, busca construir un habitus del fútbol con y desde su cultura: es "condición de posibilidad de sobrevivencia, de emancipación y crecimiento, de resistencia y liberación, de cohesión social y libertad... Lleva implícita la noción de comunidad que, a su vez, implica diversidad y diferencia" (Reascos 2011, 23). Es un ethos tejido por símbolos, vestuario, comida, música, mingas comunitarias, valores y prácticas culturales locales dinamizadas por la economía capitalista. Esta cultura es pensada, vivida y circulada en la red como noticias, relatos, videos, tuits y selfis por ciertos medios y por Juan Pablo Sorín, quien visitó Ecuador.

\section{"Hablar acerca de" Mushuc Runa y el indígena en Twitter}

¿Cómo se describe al indígena en el contexto del fútbol ecuatoriano? "La ideología dominante, la situación de opresión de los pueblos indios ha generado estereotipos, formas de representación que enclaustran al indio en una actitud de inmovilidad y debilidad" (Kowii 2006, 61). La representación del indígena inmóvil y débil es una acción comunicativa vertical, permea las estructuras del texto y del habla-discursos- en el campo del fútbol. Por eso no hay indígenas en la selección nacional del Ecuador, porque el poder decide qué miembro "de la sociedad participa, qué acciones sociales se cumplen a través del discurso" (Van Dijk 1999, 27). Sin embargo, el fútbol es parte de la vida cotidiana, de fiestas andinas como el Pawkar Raymi (Imbabura) y el Taita Carnaval (Chimborazo), y de fines de semana en la urbe y en el campo, lugares de residencia del kichwa, quien apropió e incorporó juegos externos a su ethos con "múltiples objetivos sociales y políticos, además de recreati- 
vos: fortalecer las identidades locales, expresar su pertenencia a la nación", entre otros (Villena 2018, párr. 9).

Mushuc Runa Sporting Club, junto a Imbayas (1950) y Pilahuín Tío (2013), son equipos originarios que cuestionan al poder en su campo y en diferentes épocas, tanto por el acceso como por la producción de su representación de inmóvil y débil. Es una acción discursiva basada en su identidad cultural, porque circula el nombre de equipo en kichwa (Imbayas y Pilahuín Tío) o hibridado (Mushuc Runa Sporting Club), no usa el español, sinónimo de despojo, estigmatización y genocidio. Es entonces que dice algo del indígena -acto comunicativo-, ya que "dado un contexto específico, ciertos significados y formas del discurso ejercen más influencia sobre las mentes de la gente que otros" (Van Dijk 1999, 29). Por eso, el otro es elemento de museo o, para el poder y los medios de comunicación, un alter ego que debe ser educado para incorporarlo a su realidad; es el discurso de ver, conocer, civilizar y disciplinar al otro.

No obstante, la participación de Mushuc Runa Sporting Club -con nombre indígena e inglés, financiado por una cooperativa propia, con directivos que usan el vestuario andino en un torneo oficial de la Conmebol- es un hecho histórico y discursivo de otredad e interculturalidad: "[Debemos] verlos como distintos pero iguales como sujetos de derechos" (Reascos 2011, 26). Esto llamó la atención al discurso del fútbol, porque no es un levantamiento indígena, sino un hecho cultural, un discurso-texto histórico que cuestiona la mirada hegemónica reproducida en el fútbol, la cultura y el mundo virtual.

Por tanto, ¿qué tipo de discurso deviene este hecho en el campo del fútbol y en las redes sociales? En su cuenta de Twitter (@jpsorin6), Sorín señala su afición por Mushuc Runa: "Ya tengo otro club q me simpatiza en el mundo, es en \#Ecuador! Genial historia d @ClubMushucRuna1 club/cooperativa $\mathrm{d}$ ahorro formada y q pertenece a los nativos d origen indígena,su nombre en quichua = HombreNuevo Jugarán la @Sudamericana x 1era vez".7

Historia y fútbol tejen en la red un discurso de admiración, afecto y relación entre Sorín y Mushuc Runa; todo es temporal, porque dista de las prác-

7. Este y el resto de tuits citados están reproducidos textualmente, con los errores ortotipográficos del original. En notas al pie se indica la dirección web donde se los puede encontrar; en este caso: https://bit.ly/2QQ357H 
ticas y los rituales de identidad de un hincha del fútbol. "Nativos de origen indígena" es un texto-dispositivo que logra capturar, contextualizar, fijar y hablar acerca del lugar del otro en la historia social y en el fútbol hegemónico. Es una doble representación del otro aceptada sin objeción por el usuario de la red, porque el lenguaje textual-dispositivo controla, determina cómo ver y llamar al equipo Mushuc Runa. Sorín y la red construyeron un régimen de la verdad acerca del kichwa.

En un segundo tuit, Sorín solicita más información del equipo: "Ne gustaría saber más sobre el club y su historia! Les pido a sus hinchas y a la gente de \#Ecuador q me manden info. Saber si es tal cual lo cuenta @LANACION, momentos malos y buenos... anécdotas del @ClubMushucRuna1 gracias! Abzo". 8

Twitter es un lugar de comunicación e interacción compleja y temporal en tres dimensiones: primero, 36 usuarios de la red enviaron mensajes con información del equipo de fútbol, historia, enlaces a reportajes y anécdotas; segundo, 590 usuarios retuitearon el texto de Sorín; tercero, 1331 cuentas de Twitter presionaron el botón de "Me gusta". Esta es la dinámica de construcción de información en la red: un enlace lleva a otros, un texto lleva a otros, un RT o like significa compartir, y la respuesta del público construye y reproduce la matriz cultural determinando la imagen del indígena, porque el hincha, el periodista, los medios y Sorín enuncian desde su locus, con un archivo cultural circulado en imágenes y discursos que forman su "constructo mental [...], reproducir el poder social de los grupos y del poder" (Van Dijk 1999, 26).

Pues bien, interacción e inmediatez aparecen en Twitter porque todos pueden estar conectados y compartir información. El primer mensaje de respuesta a Sorín fue de la cuenta oficial de Mushuc Runa (@ClubMushucRuna1): “@jpsorin6 un abrazo y gracias por sumarte a la hinchada del Ponchito". "Se interpreta la admiración y el interés de Sorín como signos de un nuevo "hincha del Ponchito", lo que se acompaña de afecto y agradecimiento, dos aspectos de las relaciones sociales en el mundo virtual.

\footnotetext{
8. https://bit.ly/3a6Y027

9. https://bit.ly/35MJPMr
} 
Tabla 1

Respuestas a preguntas en Twitter de Juan Sorín: @jpsorin6

\begin{tabular}{|c|c|}
\hline Responde a la inquietud & No responde a la inquietud \\
\hline 6 & 30 \\
\hline Total & 36 \\
\hline
\end{tabular}

Fuente y elaboración propia.

Las verdaderas respuestas son escasas comparadas con aquellas interacciones que no responden a la pregunta, se produce una incomunicación entre Sorín y los tuiteros. Además, por un lado, expone la escasa cultura futbolera de los usuarios acerca de un equipo ecuatoriano y, por otro, evidencia los archivos culturales que usan en su interacción textual. La comunicación discursiva es informar para fijar aspectos negativos del otro: "Donde a los extranjeros que no rinden les mandan a correr con las ovejas"; "Te cuento @ jpsorin6 que pierde el 90\% de sus partidos en serie A, solo cuando se enfrenta a Barcelona demuestran un juego aguerrido como la mayoria los equipos Ecuatorianos. Haz escuchado de @GuayaquilCityFC este es otro equipo del mismo actuar. Barcelona es el Ídolo Ecuatoriano"; "Su Presidente es muy controversial, para bien y mal. Recién construyó un estadio, pequeño. Acaba de ascender por segunda vez a la categoría A de nuestro fútbol". ${ }^{10}$

Los dos primeros tuits son de hinchas de otros equipos, mientras que el tercero es de un periodista que señala el estilo del liderazgo de Chango. El tuit (texto) oculta la matriz colonial (contexto) de mirar en el indígena todo aquello de que carece el emisor (poder), por ejemplo "ausencia de malicia al momento de jugar el fútbol", "exigir resultados del jugador", "no ser controversial sino alienado al estatus quo". Pero si esto y más lo hace un equipo tradicional y sus directivos está bien, porque así es el fútbol con dosis de picardía. Lo colonial ciega al hincha, porque en la nómina de sus equipos hay afrodescendientes, mestizos y extranjeros.

En esto aparece el indígena histórico, en un tuit que empieza así: “Genial $\mathrm{q}$ una figura del fútbol sudamericano se interese $\mathrm{x}$ un nobel club ecuatoriano

10. https://bit.ly/2RewVSh, https://bit.ly/37Y38nt y https://bit.ly/2Nh6xWw, en ese orden. 
q representa a los aborígenes". ${ }^{11}$ Mushuc Runa representa a los aborígenes, una condición per se aunque posea estudios, cooperativas, carros... Además, es parte del sistema: con su vestuario, lengua y proyecto social no dejarán de ser aborígenes. Un neoracismo niega la condición de sujeto social capaz de manipular, en el campo del fútbol, sus matrices culturales. Hay un cuerpo a cuerpo entre el fútbol y el poncho, el idioma y otros bienes culturales que da inicio a un sujeto autónomo con discurso y prácticas socioculturales para trascender y cambiar su entorno. Él no sale del sistema sino que está adentro y desde allí hace circular su discurso político y económico, aunque para el pensamiento colonial hacerse hincha de este equipo implica ser identificado con las connotaciones históricas hacia los pueblos originarios desde el poder en la sociedad de la información.

Pues bien, el primer tuit de respuesta del club a Sorín pasó a ser una invitación formal para visitar y conocer las instalaciones, dictar charlas en las oficinas de la Cooperativa Mushuc Runa acerca de sus vivencias en el fútbol, visitar a niños de una unidad educativa y, finalmente, jugar con la camiseta de Mushuc Runa en la "Tarde del Ponchito" - acto oficial para presentar la indumentaria a utilizar en la LigaPro y la Copa Sudamericana- en su estadio, ubicado en la comunidad Echaleche.

Sorín tiene peso social, cultural, político y económico en los Andes. Recibió y se puso el poncho del pueblo Pilahuín; comió cuy, conejo y habas en la casa del presidente del "Ponchito". Este acto materializa esta relación social, atravesada por aspectos culturales, económicos y políticos en el campo del fútbol. Además, Mushuc Runa lo convierte en una fiesta, porque Sorín pasa de ser un admirador a padrino del equipo ecuatoriano. En este rito de paso ocurre comunicación e interculturalidad en el fútbol.

El cuy y el conejo son apetecidos en las comunidades indígenas del país. Aquí se los come asados y acompañados con un rico ají”, aseguró Chango. Mientras, el exfutbolista sonreía por la abundante comida que recibió de parte de los dueños de casa. "Todo eso no te vas comer tú solo; ya te traemos dos presas para que las pruebes. Estos platos fueron para las fotos e indicarte que así se entrega a las personas que son designadas padrinos en las fiestas de las comunidades, aclaró Chango. (El Comercio, 2019a, párr. 3-4)

11. @andrenazo es la cuenta de Twitter que comenta en el time line de Juan Sorín, 17 de diciembre de 2018. Disponible en https://bit.ly/2NiKej6 
Sorín disfrutó de la comida, de la música andina y del paisaje ecuatoriano, y subió imágenes y videos a la red. Su presencia tuvo cobertura por parte de los medios de comunicación. Por ejemplo, El Comercio, uno de los diarios de mayor circulación en Ecuador, señaló en una publicación: "Juan Pablo Sorín ha sido elogiado por su sinceridad y espontaneidad con la que se ha mostrado en cada acto público y privado en el que apareció. El nombre del Mushuc Runa ha sonado en el mundo entero, gracias al exjugador argentino que se encariñó con el equipo, por tratarse de un club indígena que mantiene y afianza su identidad" (2019b, párr. 9).

El medio de comunicación pondera los actos del jugador, por ubicar al Mushuc Runa en el contexto mundial; en cuanto al equipo, señala que "mantiene y afianza su identidad". Es decir, el indígena es parte del sistema sin dejar de ser el otro ¿Por qué el indígena no debe cambiar, mantener y afianzar su identidad para ser parte del sistema?, ¿Por qué el poder no cambia su pensamiento colonial hacia el otro? En la red, medio y usuarios reactualizan el discurso-dispositivo colonial y perpetúan las relaciones de poder.

Sorín estuvo pendiente del debut de Mushuc Runa en Copa Sudamericana. Tres horas antes del juego publicó este texto junto con imágenes: "Se viene el debut en un torneo internacional del @ClubMushucRuna1 será x la \#Sudamericana vs UniónEspañola y es histórico! Más allá del resultado, las comunidades indígenas ecuatorianas estarán representadas y orgullosas del \#Ponchito x respetar sus raíces y a su gente!". ${ }^{12}$

Tabla 2

Reacciones al tuit de Juan Pablo Sorín en @jpsorin6

\begin{tabular}{|c|c|c|}
\hline Comentarios & RT & Me gusta \\
\hline 75 & 862 & 4.029 \\
\hline
\end{tabular}

Fuente y elaboración propia.

12. Texto del tuit de Juan Pablo Sorín, publicado el 19 de marzo de 2019. Disponible en: https:// bit.ly/36RsEuk 
Asimismo, Sorín publicó, con más imágenes, luego del primer gol de Mushuc Runa en la Copa Sudamericana: “\#postales debut y ler gol internacional en la historia del@ClubMushucRunal fue de \#Rivas después de asistencia de \#George y el grito de los hinchas del \#Ponchito Final fue empate con UniónEspañola 1-1 con \#Medina arquero, como gran figura! Se define 18.4 en \#Ecuador Abzo". 13

Tabla 3

Reacciones al tuit del debut de Mushuc Runa publicado por Sorín en @jpsorin6

\begin{tabular}{|c|c|c|}
\hline Comentarios & RT & Me gusta \\
\hline 34 & 563 & 2.548 \\
\hline
\end{tabular}

Fuente y elaboración propia.

Sorín ubica en texto e imagen los aspectos culturales y simbólicos del indígena en el fútbol profesional, y estos aspectos son los que tienen respuesta de los usuarios. Las respuestas al primer tuit visibilizan el ámbito de sentido de pertenencia, comunidad imaginada y homogénea en el fútbol: "mis hermanos indígenas", "vamos mi Ecuador multicultural" y una comunidad asentada en un pasado histórico: "equipo del pueblo...de sangre preincaica de guerreros ancestrales", que se transforma en "nuestras raíces" y en "nuestros futbolistas indígenas" ${ }^{14}$ Sorín logra "visibilizar a la comunidad indígena de nuestro pás" 15 por las redes sociales porque los medios de comunicación no le dan el realce desde la perspectiva del hincha. ¿Será que en la agenda setting de los medios de comunicación el indígena está vinculado a temas de pobreza, levantamientos, justicia indígena, y no a este otro indígena encarnado por Chango y Mushuc Runa?

\footnotetext{
13. https://bit.ly/3a4zDSQ

14. https://bit.ly/381BXIy, https://bit.ly/2tf2fbg, https://bit.ly/2N1ILZx, https://bit.ly/35LXvXW y https://bit.ly/2FKWftG, en ese orden.

15. https://bit.ly/2R8tX1q
} 
El tejido de frases en Twitter es una "nación-comunidad imaginada", pero no, como señalaba Anderson, basado en la mercancía impresa -de manera simultánea y sincrónica por el pasquín o el periódico-, sino en el tiempo-espacio de la red, que captura una representación del indígena para moldear sentimientos, gestos, miradas del tuitero hacia el otro porque deviene en otras respuestas distantes hacia el segundo tuit de Sorín: "Gracias Juanpi por apoyar al Ponchito Rojo"; "Felicidades al ponchito... Viva Ecuador y toda su gente carajo"; "el fútbol también se hace fuera de las canchas! Gracias crack" ${ }^{16} \mathrm{El}$ fútbol genera emociones y adhesiones en redes sociales, medios de comunicación y en la vida cotidiana, hasta volverse en una religión actual que busca su rey en todas las canchas-templos del mundo.

Estos mensajes toman distancia hacia el otro, es desapego emocional y territorial reproducido en lo cotidiano. Ellos no quieren compromisos, evitan ser estigmatizados por otros hinchas y usuarios de la red, ya que lo indígena no es orgullo ni tampoco una base sólida en su construcción discursiva de identidad, sino una estrategia discursiva temporal que oculta su vergüenza hacia lo indígena; es racismo en el campo del fútbol. Además, sitúa que su amor del hincha por el equipo aparecerá en discursos-textos, sea para equiparar, valorar o subestimar a otros equipos; es ambivalencia identitaria y discursiva al infinito.

Así, la respuesta-texto del usuario es su imagen y representación del indígena, aprendida, incorporada y reproducida en el campo del fútbol, representación temporal e histórica. Lo temporal es superado por lo histórico, legitimado por las instituciones, que forma el régimen de la verdad. También diseminan el poder en términos de saber-conocimiento, que construye cuerpos dóciles incorporados a las estrategias de poder.

Hablar acerca de es saber y poder, discurso circulado en Twitter que perpetúa aspectos históricos del indígena; por ende, es el no-lugar que va con nosotros, señala Augé (2000). Es una extensión del ser, porque la comunicación es arista central en los procesos históricos. "McLuhan dirá que estamos en una 'aldea global' construida y gestionada en base a las tecnologías audiovisuales de la comunicación" (Remondino 2012, 52): es un dispositivo que condiciona y sujeta al indígena en discursos neocoloniales.

16. https://bit.ly/2tQ2ZUm, https://bit.ly/30eQQo0 y https://bit.ly/2R9j0wF, en ese orden. 


\section{Conclusiones}

El presente texto buscó evidenciar la representación del indígena en el fútbol ecuatoriano. Para esto, hizo un análisis de discurso a tuit (textos) en la red social Twitter. El lenguaje captura al indígena en un discurso histórico, político y cultural reproducido en la vida social. Es un lenguaje que fija un régimen de la verdad acerca del kichwa desde la Conquista de Abya-Yala hasta nuestros días. El poder hegemónico ha elaborado, por más de cinco siglos, un archivo cultural que aparece en discursos, relatos, textos e imágenes con nuevos ropajes, basado en nociones viejas de tiempo, espacio, raza, género, entre otros, que justifican ver al otro y a todo su universo simbólico como inferior, como aquello para ser conocido, civilizado e incorporado a la estructura y lógica del poder.

El usuario del Twitter habla acerca de Mushuc Runa Sporting Club con elementos simbólicos y discursivos en el campo del fútbol porque son un régimen de la verdad fijado por la educación, la religión, los medios y el poder político. Es decir, el fútbol reproduce la representación del indígena del mundo social porque el indígena existe para la construcción de la identidad del blanco-mestizo. El indígena es inmóvil, sin agencia e incapaz de ser parte de y jugar en el campo del fútbol; esta es la razón de su ausencia en la selección nacional del Ecuador.

Sin embargo, este texto ha intentado mostrar que el kichwa interactúa en el campo del fútbol desde su matriz cultural y lógica de vida. Lo ha hecho desde 1950 con el equipo Imbayas y en torneos no profesionales en fiestas andinas. El fútbol es apropiado y resignificado por el indígena desde la dimensión de la cultura, lugar de comunicación entre los sujetos sociales. El indígena no se mira inferior al otro sino igual, por eso habla y vive la interculturalidad. Adopta los símbolos impuestos por el poder para transformarlos en símbolos de su identidad, que dialogan con la minga, la comida, la reciprocidad y la música para formar un discurso que disputa sentidos y significados en el campo del fútbol.

Con este discurso cuestiona las imágenes fijadas como verdad. El poder solo se remite al archivo cultural, que no logra reconocer la habilidad del kichwa y tampoco puede dar nombre a esta forma de disputa simbólica, ya que habla de identidad, de ancestros. Es una mirada que devela la caducidad 
del archivo histórico, porque no sabe cómo llamar a este indígena con bienes simbólicos del poder incorporados en su propio reservorio simbólico.

¿Son válidas las categorías de híbrido, alienado, blanqueado para este kichwa? ¿Por qué el indígena es visto desde la identidad y no desde la autonomía y emancipación en lo cotidiano? ¿Acaso el fútbol debe verse más allá del negocio y situar en su análisis las dimensiones de interculturalidad y plurinacionalidad circuladas por los indígenas? Estas preguntas, entre otras, surgen para ser abordadas en otro texto, porque este funge de pequeña introducción para mirar al fútbol desde la dimensión de la cultura.

Otra conclusión es que el archivo cultural es limitado al momento de llamar al indígena que prospera, habla, piensa y se moviliza en el campo del fútbol, porque no basta con asombrarse de su capacidad ni con señalar su lugar en la historia lineal de Occidente. El indígena ha dado el salto para llamarse ser humano (runa) con agencia y creatividad; en términos de Silvia Rivera (2015), autónomo y emancipado en el fútbol, para sí y para otros, con su universo simbólico. Una descolonización del indígena en el fútbol. Aunque el caso de Mushuc Runa Sporting Club es solo un ejemplo de prosperidad y emancipación, porque el indígena sigue en condiciones de extrema pobreza, sin acceso a educación, alimentación y vivienda. Esta población encarna la escasez, entendida como producto de la inequidad social dominante en Ecuador. Mira el fútbol como espacio para cambiar su realidad, creando un ethos del fútbol con sus matices locales.

\section{Referencias}

Agamben, Giorgio. 2014. ¿Qué es un dispositivo? Buenos Aires: Anagrama.

Alcalá, Miryam. 2017. "La galaxia internet: reflexiones sobre internet, empresa y sociedad". Revista Mexicana de Ciencias Politicas y Sociales (231): 407-412. https://bit.ly/2zc8i3e

Almudena Moreno, Mínguez y Carolina Suárez. 2010. "Las comunidades virtuales como nuevas formas de relación social: elementos para el análisis”. Espéculo. Revista de Estudios Literarios (43): 1-11. https://bit.ly/2Scu9ih

Amador, Julio. 2018. El arte rupestre como medio de comunicación: observaciones de método sobre su interpretación. Ciudad de México: UNAM.

Augé, Marc. 2000. Los no lugares, espacios de anonimato: una antropología de la sobremodernidad. Barcelona: Gedisa. 
Bendito Fútbol. 2018. "Presidente de la Conmebol recibió el poncho del Mushuc Runa". Bendito Fútbol. Accedido 13 de enero de 2020: https://bit.ly/2MgIcQb

Butler, Judith. 2004. Lenguaje, poder e identidad. Madrid: Síntesis.

Calsamiglia, Helena, y Amparo Tusón. 2002. El análisis del discurso: en las cosas del decir. Manual de análisis del discurso. Barcelona: Ariel.

Castells, Manuel. 2001. La Galaxia Internet: reflexiones sobre Internet, empresa y sociedad. Barcelona: Plaza \& Janés.

Chango, Alfonso. 2019. Entrevistado vía telefónica por FM 88 Radio Activa de Cuenca, 15 de febrero.

EC 1830. Constitución de la República del Ecuador. Registro Oficial 93, 23 de septiembre.

---. 2008. Constitución de la República del Ecuador. Registro Oficial 449, 20 de octubre.

El Comercio. 2018a. "Presidente del Mushuc Runa: 'El estadio reactivará a pueblos rurales' ". El Comercio. Accedido 13 de enero de 2020: https://bit.ly/383fPNP

---. 2018b. "Mushuc Runa estrenó su estadio en la comunidad de Echaleche". El Comercio. Accedido 13 de enero de 2020: https://bit.ly/2MfOIIM

---. 2019a. "Juan Pablo Sorín comió cuy, conejo y habas en la casa de Luis Chango". El Comercio. Accedido 13 de enero de 2020: https://bit.ly/35IBolT

---. 2019b. "Después de jugar ante Emelec, Juan Pablo Sorín paró en la carretera a comer fritada". El Comercio. Accedido 13 de enero de 2020: https://bit.ly/2MiQqYa

Endara, Lourdes. 1998. El marciano de la esquina: imagen del indio en la prensa ecuatoriana durante el levantamiento indígena de 1990. Quito: Abya-Yala.

Gil, Paloma. 2009. "Comunicación rupestre: de cueva en cueva”. Razón y Palabra. Accedido 13 de enero de 2020. https://bit.ly/2S1bBkE

Hall, Stuart. 1997. Representaciones socioculturales. Londres: Sage Publications.

---. 2010. Sin garantías: trayectorias y problemáticas en estudios culturales. Quito: Universidad Andina Simón Bolívar / Instituto de Estudios Peruanos / Pontificia Universidad Javeriana / Instituto de Estudios Sociales y Culturales Pensar.

Kowii, Ariruma. 2006. "Etnias y fútbol en los kichwa de Imbabura: el caso de los kichwa otavalo”. En El jugador número 12: fútbol y sociedad, editado por Fernando Carrión, 6174. Quito: FLACSO.

Lajo, Javier. 2006. Qhpaq Ñan: la ruta inka de sabiduría. Quito: Abya-Yala.

López, Oscar. 2018. "Significados y representaciones de la minga para el pueblo indígena Pastos de Colombia”. Psicoperspectivas 17 (3): 1-13. http://dx.doi.org/10.5027/psicoperspectivas/vol17-issue3-fulltext-1353

Maisanche, Fabián. 2019. "Juan Pablo Sorín comió cuy, conejo y habas en la casa de Luis Chango". Accedido 2 de febrero. https://www.elcomercio.com/deportes/sorin-cuy-chango-mushuc- runa.html 
---. 2018. "Presidente de la Conmebol recibió el poncho del Mushuc Runa". 18 de noviembre. https://www.benditofutbol.com/nacional/presidente-conmebol-recibio-poncho-mushuc. $\mathrm{html}$

--- 2018. "Presidente del Mushuc Runa: 'El estadio reactivará a pueblos rurales'”. 19 de noviembre. https://www.elcomercio.com/deportes/presidente-mushuc-runa-estadio-rural. html

Manzanero, Fernando. 2000. "Monedas romanas, acápite 14. Monedas y propagandas". Junta de Andalucía. Accedido 15 de octubre de 2019. http://www.juntadeandalucia.es/averroes/ centros-tic/14002996/helvia/aula/archivos/repositorio/250/263/html/Nomisma/sis/sis.htm

Martín-Barbero, Jesús. 2012. “De la comunicación a la cultura: perder el 'objeto' para ganar el proceso". Signo y Pensamiento 30 (60): 76-84. https://doi.org/10.11144/Javeriana.syp3060.dccp

Muñoz, Alfonso, e Irina Argüelles. 2010. "Análisis del discurso en redes sociales: Twitter, un caso bajo estudio". Ponencia presentada en el XXVIII Congreso Internacional de la Asociación Española de Lingüística Aplicada. Vigo. https://bit.ly/36NwTXA

Muratorio, Blanca. 1994. Imágenes e imagineros: representaciones de los indigenas ecuatorianos: siglos XIX y XX. Quito: FLACSO.

Oliven, Ruben, y Damo Arlei. 2001. Fútbol y cultura. Bogotá: Norma.

Ong, Walter. 1987. Oralidad y escritura: tecnologías de la palabra. Ciudad de México: Fondo de Cultura Económica.

Reascos, Nelson. 2011. "La cultura, las culturas y la identidad". En Estado del país. Informe cero. Ecuador 1950-2010, coordinado por FLACSO Ecuador y Contrato Social por la Educación, 23-27. Quito: Estado del país.

Remondino, Georgina. 2012. "Blog y redes sociales: un análisis desde las tecnologías de la gubernamentalidad y el género". Athenea Digital 12 (3): 51-69. http://www.redalyc.org/ articulo.oa?id=53724611004

Rivera, Silvia. 2015. Sociología de la imagen: miradas ch'ixi desde la historia andina. Buenos Aires: Tinta Limón.

Spedding, Alison. 2008. Religión en los Andes: extirpación de idolatrías y modernidad de la fe andina. La Paz: Artes Gráficas Sagitario.

StudioFutbol. 2013. ¿Cómo llegó el fútbol a Ecuador? Accedido 2 de agosto de 2019. http:// studiofutbol.com.ec/2013/04/26/como-llego-el-futbol-a-ecuador/

Tixi, Alexander. 2018. Elementos semióticos que construyen la identidad cultural en Tungurahua. Estudio de caso: Mushuc Runa Sporting Club (2018). Quito: FLACSO.

Tuhiwai, Linda. 2016. A descolonizar las metodologías: investigación y pueblos indigenas. Santiago de Chile: Lom Ediciones.

Van Dijk, Teun. 1999. "El análisis crítico de discurso". Anthropos: Huellas del Conocimiento (186): 23-36. https://dialnet.unirioja.es/servlet/articulo?codigo=230577

Velásquez, Diva. 2006. "La imagen en el arte medieval". Mediaciones 4 (6): 11-19. https:// bit.ly/3a6wvWv 


\section{Alfredo Bagua}

Villena, Sergio. 2009. "Del fútbol y otros demonios: fútbol, religión y nacionalismo en Costa Rica”. Anuario de Estudios Centroamericanos, Universidad de Costa Rica (35-36): $137-$ 147. https://www.redalyc.org/articulo.oa?id=15233433007

---. 2018. La colonialidad del poder: el fútbol, la nación y los pueblos indígenas. San José de Costa Rica: Izcalde.

Zarza, Gloria de los Ángeles. 2017. "El fútbol como fiesta, el balón como bandera”. Amérique Latine Histoire et Mémoire. Les Cahiers ALHIM. Accedido 25 de septiembre de 2019. http://journals.openedition.org/alhim/5697 